\title{
Financial Burden in Families of Children with West Syndrome
}

\author{
Dhvani Raithatha ${ }^{1} \cdot$ Jitendra Kumar Sahu ${ }^{2}$ (D) Singanamalla Bhanudeep ${ }^{2} \cdot$ Lokesh Saini $^{2} \cdot$ Shankar Prinja $^{3}$. \\ Bhavneet Bharti ${ }^{1}$ - Priyanka Madaan ${ }^{2}$. Saroj Kumar Rana ${ }^{3} \cdot$ Sandeep Negi ${ }^{2}$
}

Received: 22 October 2020 / Accepted: 31 March 2021 / Published online: 26 May 2021

(C) Dr. K C Chaudhuri Foundation 2021

\begin{abstract}
Objective To evaluate the illness-related expenditure by families of children with West syndrome (WS) during the first year of illness and to explore the potential determinants of the financial drain.

Methods This cross-sectional study was conducted at a tertiary care hospital between July 2018 and June 2020. Eighty-five children with WS who presented within one year from the onset of epileptic spasms were included. The details of the treatment costs (direct medical and nonmedical) incurred during the first year from the onset of epileptic spasms were noted from a parental interview and case record review. Unit cost was fixed for drugs and specific services. Total cost was estimated by multiplying the unit cost by the number of times a drug or service was availed. The determinants of the financial burden were also explored. Results The median monthly per-capita income of the enrolled families $(n=85)$ was INR $3000(\mathrm{Q} 1, \mathrm{Q} 3,2000,6000)$. The median cost of treatment over one year was INR 27035 (Q1, Q3, 17,894, 39,591). Median direct medical and nonmedical expenses amounted to INR 18802 (Q1, Q3, 12,179, 25,580) and INR 6550 (Q1, Q3, 3500, 15,000), respectively. Seven families had catastrophic healthcare expenditure. Parental education and choice of first-line treatment were important determinants driving healthcare expenses. The age at onset of epileptic spasms, etiology, treatment lag, the initial response to treatment, and relapse following initial response did not significantly influence the illness-related expenditure by the families.

Conclusion WS imposes a substantial financial burden on the families and indirectly on the healthcare system.
\end{abstract}

Keywords Infantile spasms $\cdot$ Financial burden $\cdot$ Cost of illness $\cdot$ India $\cdot$ Children

\section{Introduction}

West syndrome (WS) is characterized by clustered epileptic spasms in infancy and hypsarrhythmia on electroencephalogram (EEG) [1]. It is the most common type of infantile-onset developmental and epileptic encephalopathy. A recent study from the United Kingdom suggested that the incidence of WS is 6.7 (95\% CI 1.2-5.7)/10,000 live births [2]. It is expected to be higher in developing countries with a higher incidence of

Jitendra Kumar Sahu

jsh2003@gmail.com

1 Department of Pediatrics, Postgraduate Institute of Medical Education and Research, Chandigarh, India

2 Pediatric Neurology Unit, Department of Pediatrics, Postgraduate Institute of Medical Education and Research, Chandigarh, India

3 School of Public Health \& Community Medicine, Postgraduate Institute of Medical Education and Research, Chandigarh, India perinatally acquired brain injuries, e.g., hypoxic-ischemic and hypoglycemic brain injury [3]. These children often have comorbidities, including developmental delay, locomotor, visual, and hearing impairment necessitating multidisciplinary care for holistic management. The first-line treatment options include adrenocorticotropic hormone (ACTH), oral steroids, and vigabatrin [4]. The short-term management goals are enduring cessation of epileptic spasms and resolution of hypsarrhythmia, which are achieved in nearly one-third of patients after first-line therapy [5]. The long-term neurodevelopmental outcome is often poor and depends on the initial therapeutic response [6]. Unlike the developed countries, the management of WS in India and developing countries has its own intricacies. These include a long treatment lag, preponderance of structural etiology, lack of awareness, and out-of-pocket expenditure for healthcare utilization $[5,7]$. Besides, two of the three first-line therapeutic options (ACTH and vigabatrin) are quite expensive, with ACTH often requiring hospitalization for the initiation and monitoring of adverse effects. Vigabatrin is not readily available in India. Considering the comorbidities, cost of drugs, and long-term 
treatment, illness-expenditure might be catastrophic for a lowincome family. The financial burden borne by the families having children with WS has not been systematically studied in India.

The financial burden is usually quantified in terms of direct, indirect, and intangible costs due to a specific disease [8]. The direct costs can be classified into medical costs (related to prevention, diagnosis, treatment, and rehabilitation) and nonmedical costs (related to travel for hospital visits, food and accommodation, etc.). The indirect costs are estimated in terms of loss of earnings, time, and attributed value of the lost household work. Furthermore, the intangible costs include stress, suffering, or anxiety due to the illness or its treatment [9]. The majority of the studies in adults with epilepsy have focussed primarily on the direct costs because of the inherent difficulty in computing the indirect and intangible costs $[8,9]$. WS poses a distinct challenge because of infantile-onset, costly investigations and treatment, and comorbidities management. A lack of universal health insurance in India further contributes to the financial burden handled by the families. Therefore, the present study was performed to evaluate financial spending (direct costs) during the first year of illness in children with WS. Besides, an attempt was made to explore the possible determinants of the financial drain.

\section{Material and Methods}

This cross-sectional, descriptive, observational study was conducted between July 2018 and June 2020 in the Department of Pediatrics, Postgraduate Institute of Medical Education and Research, Chandigarh, a tertiary-care government children hospital in North India. The study was approved by the Institute Ethics Committee. Children with WS (epileptic spasms and hypsarrhythmia in EEG) attending outdoor clinics of the Pediatric Neurology unit were screened. All consecutive children who presented within one year from the onset of epileptic spasms were considered eligible for inclusion. Detailed informed consent was obtained from the parents at the time of enrollment. Those who declined consent were excluded from the study.

The parents/guardians of the enrolled children were interviewed for the sociodemographic aspects and details of the treatment costs incurred. The clinical and investigational details were retrieved from the medical records. The data on demographic characteristics, age at onset of epileptic spasms, presence of any specific perinatal insult, parental educational status, monthly family income, delay in seeking treatment, diagnosis, and the start of appropriate first-line treatment were collected. It was noted whether the children were beneficiaries under the poor free scheme for below poverty line (BPL) families. The criterion for inclusion in the BPL facility was a provision of yellow ration cards to the families by the
Government of India. It was also noted whether infants were benefitted from Janani Shishu Suraksha Karyakram (JSSK).

The costs incurred in a year were determined by interviewing the caregivers. The bottom-up approach of cost analysis was used wherein, every single area of expenditure was calculated. Costs were categorized as: a) direct medical costs including the cost of outpatient consultation, hospital admission, drugs, investigations, and ancillary services; $b$ ) direct nonmedical costs involving an expenditure of travel to and from the health setup, the cost of food, and accommodation while being stationed at the hospital with the child (two caregivers per patient).

Unit cost (under the direct medical costs) was fixed for each commodity based on the price at the index institute (Supplementary Table 1). Total cost was calculated by multiplying the unit cost by the number of times a service or product was availed. Direct nonmedical costs were noted at first admission (or at first contact for those who were never admitted) at the index institute, and it was assumed that the pattern of expenditure on these components remained the same throughout the year. Parents were interviewed at the first visit and asked to keep records of the purchases being made for drugs and investigations. They were followed-up 3-monthly to gather data of expenditure made in the past 3 mo. The expenses made on drugs and investigations were crosschecked from the medical records. Children belonging to BPL families and under the JSSK scheme were exempted from expenses made on investigations and hospital admission charges. The expenditure was calculated in Indian rupee (INR) and the United States dollar (USD) as on August 8, 2020. Figure 1 shows an outline of potential cost-driving factors considered during the collection of data. Annual direct medical and nonmedical costs were calculated, and their relationship with sociodemographic and disease-specific variables was analyzed.

Statistical Analysis Descriptive statistics like mean, median, interquartile range (IQR), and 95\% confidence interval were used for various heads of total expenses and their determinants. The sign test was employed to study the significance of the median value of total cost among its determinants. All calculations were done with $p$ value level of $\leq 0.05$ as statistically significance. The analysis was done by the Statistical Package for the Social Sciences (SPSS) 22.0 version (IBM Corporation, USA).

\section{Results}

A total of 138 children were initially enrolled. However, there was significant attrition of 53 children (38\%) due to follow-up difficulties and inability to provide accurate details on financial expenditure incurred over one year. Hence, 85 children 


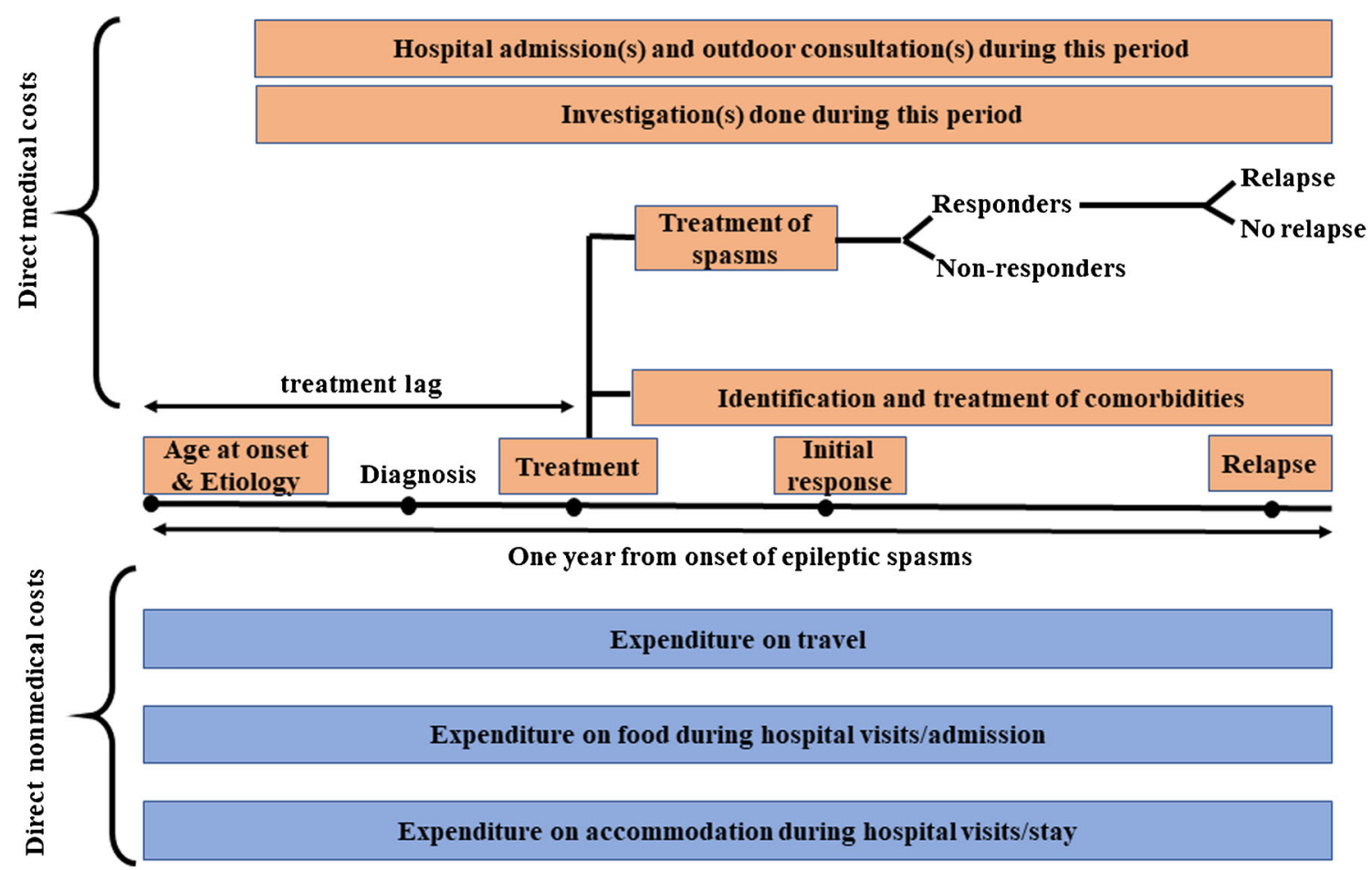

Fig. 1 Potential factors contributing to the financial burden on families of children with West syndrome

(67 boys) completed the one-year follow-up and formed the study population. The majority of the children were from North India. Statewise distribution was as follows: Haryana $(\mathrm{n}=30,35.3 \%)$, Punjab $(\mathrm{n}=22,25.9 \%)$, Himachal Pradesh $(\mathrm{n}=15,17.6 \%)$, Chandigarh $(\mathrm{n}=8,9.4 \%)$, Jammu and Kashmir $(n=3,3.5 \%)$, Uttarakhand $(n=2,2.3 \%)$ and Uttar
Table 1 Demographics of the study population

\begin{tabular}{ll}
\hline Characteristics & Total (n=85) \\
\hline No. of boys & 67 \\
No. of girls & 18 \\
No. of children from urban area & 41 \\
No. of children from rural area & 44 \\
No. of children requiring hospital admission & 54 \\
No. of children requiring hospital admission twice & 9 \\
No. of children requiring hospital admission more than two times & 1 \\
Rehabilitative services availed by & 85 \\
No. of families that spent money on accommodation & 12 \\
No. of families that spent money on food & 45 \\
No. of children with complete response to primary treatment & 34 \\
No. of children with relapse following complete response to primary treatment & 7 \\
Age at onset of spasms; median (IQR) & $7.5(5-10)$ \\
Age at enrolment; median (IQR) & 9.5 (7-13) \\
No. of days of IPD admission; median (IQR) & 4 (5.3) \\
OPD charges; median (IQR) & 30 (30) [0.4 USD] \\
IPD charges; median (IQR) & $460(615)$ [6.1 USD] \\
Drugs charges; median (IQR) & $15,286(11205)$ [203.7 USD] \\
Travel charges; median (IQR) & 5000 (11580) [66.6 USD] \\
Food charges; median (IQR) & $360(1225)$ [4.8 USD] \\
\hline
\end{tabular}

Costs described in Indian rupee (INR); values in square brackets have cost in US dollar (conversion as of August $8,2020, \$ 1=75.04)$

$I P D$ Inpatient department, IQR Interquartile range, OPD Outpatient department rupees, USD US dollar 
Pradesh $(n=2,2.3 \%)$. Three $(3.5 \%)$ children were from distant states: Bihar $(\mathrm{n}=2)$ and Madhya Pradesh $(\mathrm{n}=1)$. Among the study cohort, 44 children belonged to rural areas, while 41 were from urban areas. The median monthly per capita income of families enrolled was INR 3000 (USD 40), IQR: (2000, 6000; USD 26.6, USD 79.9). The demographics of the study population have been detailed in Table 1 .

The median age at onset of epileptic spasms was 7.5 (IQR 511) mo. A structural etiology was observed in 71 (83.5\%) children, whilst 14 (16.5\%) had presumed genetic etiology. Structural causes were as follows: hypoxic-ischemic brain injury $(\mathrm{n}=34,48 \%)$, neonatal hypoglycemic brain injury $(\mathrm{n}=18$, $25 \%)$, postmeningitic hydrocephalus $(n=5,7 \%)$, intracranial hemorrhage sequelae $(n=4,6 \%)$ and others $(n=10,14.0 \%)$. Of 14 children with presumed genetic etiology, two were tested with clinical exome sequencing. Constipation $(n=18,21.1 \%)$, visual impairment $(\mathrm{n}=13,15.2 \%)$, gastroesophageal reflux $(\mathrm{n}=$ $6,7.0 \%)$, hearing impairment $(n=5,5.8 \%)$, hemiparesis $(n=3$, $3.5 \%)$, infantile tremor syndrome $(\mathrm{n}=2,2.3 \%)$, congenital heart disease $(\mathrm{CHD} ; \mathrm{n}=2,2.3 \%)$ and hypothyroidism $(\mathrm{n}=1,1.2 \%)$ were notable comorbidities apart from global developmental delay. Three children had Down syndrome (one had comorbid CHD and hypothyroidism, and one had CHD alone). The median diagnostic lag was $7 \mathrm{wk}(\mathrm{Q} 1, \mathrm{Q} 3,3,16 \mathrm{wk})$, and the median treatment lag was $10 \mathrm{wk}(\mathrm{Q} 1, \mathrm{Q} 3,4.7,18.2 \mathrm{wk})$. Initial therapeutic choices were ACTH $(n=58,68.2 \%)$, prednisolone $(n=20$, $23.5 \%)$, and vigabatrin $(n=7,8.2 \%)$. Of 85 children, 49 received only one of the first-line drugs. Crossover of first-line drugs was seen in $36(42.3 \%)$ children. Of 58 children with initial ACTH therapy, 4 subsequently received high-dose prednisolone, 11 vigabatrin, and 6 a combination of prednisolone and vigabatrin. Of 20 children with initial high-dose oral prednisolone therapy, 3 were subsequently received ACTH, 6 vigabatrin, and 1 a combination of $\mathrm{ACTH}$ and vigabatrin. Of seven with initial vigabatrin therapy, 3 subsequently received $\mathrm{ACTH}$, and 2 oral prednisolone. Complete response, as defined by enduring cessation of epileptic spasms for $4 \mathrm{wk}$, to any of the first-line therapies was seen in $40 \%$ of children $(n=34)$. Of those with complete response, $20.5 \%(n=7)$ had a relapse requiring additional antiseizure medications. Relapse was defined by a recurrence of epileptic spasms after achieving a complete initial response.

The median cost of treatment was INR 27035 (Q1, Q3, 17,894, 39,591; USD 238.4, USD 527.5). Median direct medical expenses amounted to INR 18802 (USD 250.6) (Q1, Q3, 12,179, 25,580; USD 162.3, USD 340.8), and nonmedical expenses amounted to INR 6550 (USD 87.3) (Q1, Q3, 3500, 15,000; USD 46.6, USD 199.8). Eight patients in the present study received government assistance under the BPL scheme. Seven patients in the study had catastrophic healthcare expenditure (CHE), i.e., healthcare expenditure was more than $30 \%$ of total family income during the study period. depict the distribution of expenditure made over $1 \mathrm{y}$ from the onset of epileptic spasms Fig. 2.

The families coming from nearby states of Punjab, Haryana, and Chandigarh spent significantly less than those coming from far-off states (Table 2). There was no significant difference in the median expenditure based on the gender of the child, locality of residence (rural versus urban), and occupation of parents. However, the cost borne by parents with higher educational status was significantly more.
Fig. 2 Utilitywise distribution of annual expense incurred by families of children with West syndrome

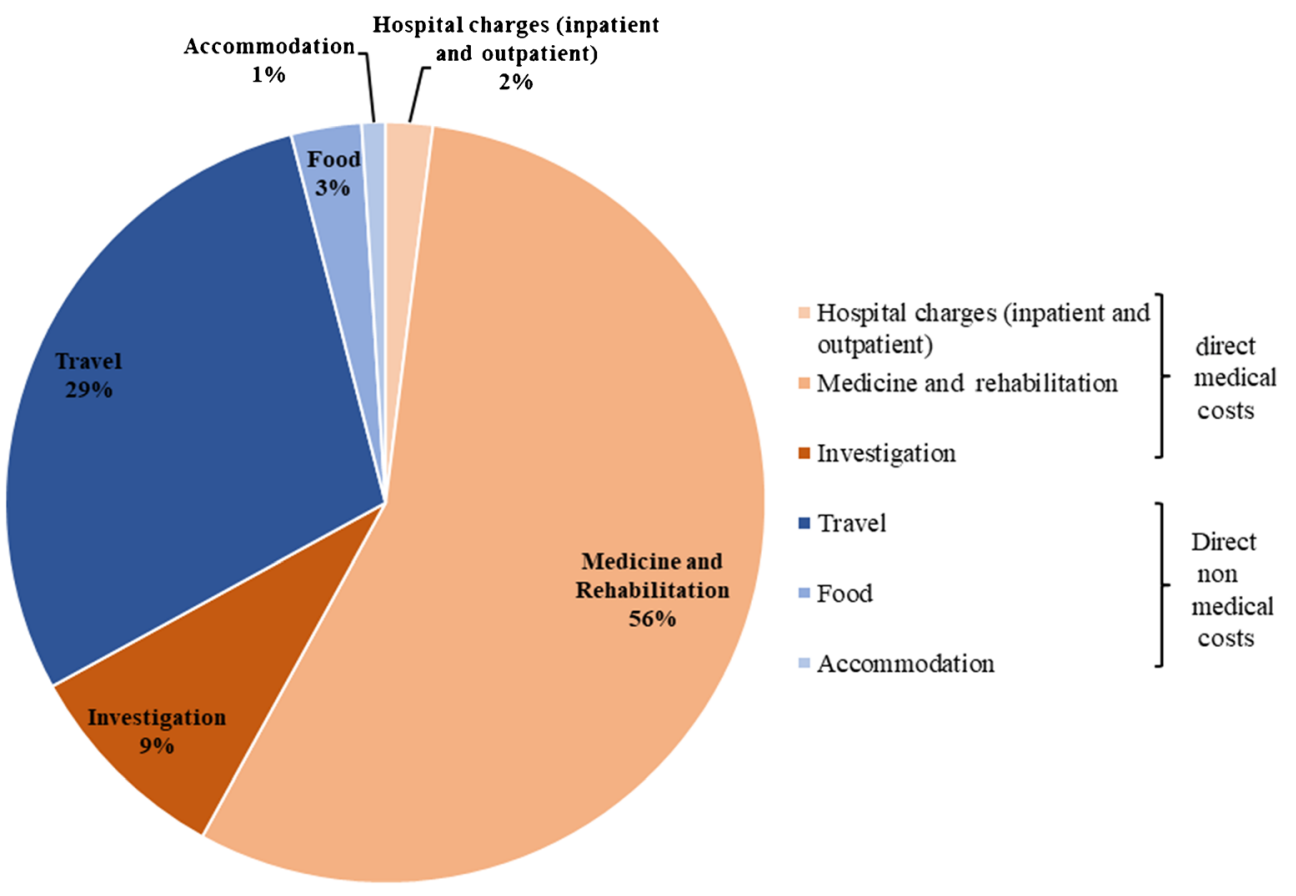


Table 2 Sociodemographic determinants of the total cost incurred by families of children with West syndrome

\begin{tabular}{|c|c|c|c|c|c|c|c|c|}
\hline \multirow[t]{2}{*}{ Factors } & \multirow[t]{2}{*}{ Variables } & \multirow[t]{2}{*}{$\mathrm{N}$} & \multirow[t]{2}{*}{ Median total cost in INR } & \multicolumn{2}{|l|}{ IQR } & \multicolumn{2}{|l|}{$95 \% \mathrm{CI}$} & \multirow[t]{2}{*}{$p$ value } \\
\hline & & & & Q1 & Q3 & Lower limit & Upper limit & \\
\hline Gender & $\begin{array}{l}\text { Male } \\
\text { Female }\end{array}$ & $\begin{array}{l}67 \\
18\end{array}$ & $\begin{array}{l}26,815 \\
29,812\end{array}$ & $\begin{array}{l}17,894 \\
16,859\end{array}$ & $\begin{array}{l}37,763 \\
42,923\end{array}$ & $\begin{array}{l}25,252 \\
22,625\end{array}$ & $\begin{array}{l}34,626 \\
36,790\end{array}$ & 0.75 \\
\hline Locality & $\begin{array}{l}\text { Urban } \\
\text { Rural }\end{array}$ & $\begin{array}{l}41 \\
44\end{array}$ & $\begin{array}{l}27,035 \\
27,076\end{array}$ & $\begin{array}{l}13,410 \\
20,938\end{array}$ & $\begin{array}{l}39,890 \\
39,278\end{array}$ & $\begin{array}{l}23,036 \\
25,734\end{array}$ & $\begin{array}{l}37,363 \\
33,470\end{array}$ & 0.92 \\
\hline State of residence & $\begin{array}{l}\text { Chandigarh, Punjab, or Haryana } \\
\text { Other states** }\end{array}$ & $\begin{array}{l}60 \\
25\end{array}$ & $\begin{array}{l}23,452 \\
37,763\end{array}$ & $\begin{array}{l}16,423 \\
26,027\end{array}$ & $\begin{array}{l}35,163 \\
46,276\end{array}$ & $\begin{array}{l}22,300 \\
30,197\end{array}$ & $\begin{array}{l}28,961 \\
50,031\end{array}$ & $<0.01 *$ \\
\hline Education of father & $\begin{array}{l}\text { Illiterate } \\
\text { Up to class } 12 \\
\text { College graduate and above }\end{array}$ & $\begin{array}{l}5 \\
50 \\
30\end{array}$ & $\begin{array}{l}18,389 \\
22,379 \\
38,396\end{array}$ & $\begin{array}{l}7875 \\
15,098 \\
30,541\end{array}$ & $\begin{array}{l}30,244 \\
30,026 \\
45,215\end{array}$ & $\begin{array}{l}7067 \\
20,484 \\
33,402\end{array}$ & $\begin{array}{l}30,784 \\
27,978 \\
48,897\end{array}$ & $<0.01 *$ \\
\hline Education of mother & $\begin{array}{l}\text { Illiterate } \\
\text { Up to class } 12 \\
\text { College graduate and above }\end{array}$ & $\begin{array}{l}7 \\
45 \\
33\end{array}$ & $\begin{array}{l}13,519 \\
23,834 \\
36,545\end{array}$ & $\begin{array}{l}7265 \\
16,809 \\
26,008\end{array}$ & $\begin{array}{l}19,808 \\
31,899 \\
44,739\end{array}$ & $\begin{array}{l}8148 \\
21,581 \\
30,900\end{array}$ & $\begin{array}{l}22,439 \\
32,894 \\
42,306\end{array}$ & $<0.01 *$ \\
\hline Occupation of father & $\begin{array}{l}\text { Unemployed } \\
\text { Employed }\end{array}$ & $\begin{array}{l}1 \\
84\end{array}$ & $\begin{array}{l}- \\
26,815\end{array}$ & $\begin{array}{l}- \\
17,470\end{array}$ & $\begin{array}{l}- \\
39,278\end{array}$ & $\begin{array}{l}40,680 \\
25,753\end{array}$ & $\begin{array}{l}40,680 \\
33,771\end{array}$ & - \\
\hline Occupation of mother & $\begin{array}{l}\text { Unemployed } \\
\text { Employed }\end{array}$ & $\begin{array}{r}73 \\
12\end{array}$ & $\begin{array}{l}26,539 \\
34,675\end{array}$ & $\begin{array}{l}17,208 \\
37,426\end{array}$ & $\begin{array}{l}37,426 \\
44,521\end{array}$ & $\begin{array}{l}24,885 \\
24,397\end{array}$ & $\begin{array}{l}33,608 \\
43,216\end{array}$ & 0.33 \\
\hline Financial assistance & $\begin{array}{l}\text { BPL government assistance } \\
\text { Self-financed }\end{array}$ & $\begin{array}{l}8 \\
77\end{array}$ & $\begin{array}{l}16,460 \\
28,143\end{array}$ & $\begin{array}{l}6042 \\
19,160\end{array}$ & $\begin{array}{l}20,605 \\
40,379\end{array}$ & $\begin{array}{l}9098 \\
27,152\end{array}$ & $\begin{array}{l}22,534 \\
35,553\end{array}$ & $0.03 *$ \\
\hline
\end{tabular}

*p value $<0.05$ was considered as statistically significant; **Other states include Jammu \& Kashmir, Himachal Pradesh, Uttar Pradesh, Uttarakhand, Bihar, and Madhya Pradesh

CI Confidence interval, INR Indian rupee, IQR Interquartile range, Q1 First quartile, Q3 Third quartile, USD US dollar

Expenditure on the illness was considerably less in families receiving government assistance under the BPL scheme.

Looking at the disease-specific parameters, age at onset, etiology, the initial response to treatment, and relapse following initial response did not significantly influence the costs borne by the families (Table 3). The cost of treatment was slightly lower in those with a longer treatment lag. Children initiated on expensive drugs like ACTH and vigabatrin had higher medical costs as compared with those who started on prednisolone. It was seen that choice of primary therapy (ACTH vs. steroids) was driven by the affordability of the families.

\section{Discussion}

With India's public health expenditure being less than $2 \%$ of GDP [10], it is important to evaluate the out-of-pocket expenditure and understand the distribution of costs for healthcare utilization for different chronic disorders. WS, often associated with multiple comorbidities, merits attention in this regard. This will not only assist in the identification of cost-effective management strategies but also guide administrative authorities in reducing the burden on families by recognizing important issues related to licensing and availability of drugs, and increasing government aid and expenditure on healthcare infrastructure.

The current study evaluated the expenditure on children with WS from diverse economic backgrounds and different states. The median age at onset of epileptic spasms in the present study population and a preponderance of the male gender was in agreement with the reported literature from India [6]. The most common etiology was structural, with adverse perinatal insults such as hypoxic-ischemic encephalopathy, neonatal hypoglycemia, and neonatal meningitis being the predominant causes. This was concordant with previously published literature $[5,6,11-13]$. The median diagnostic and treatment lag were significant and were comparable to that reported in different Indian studies [5, 6, 11-13].

The median direct medical cost in the first year of illness exceeded the direct nonmedical costs. Like other studies evaluating the costs involved in the management of epilepsy and refractory epilepsy syndromes, the cost of medications formed the major bulk of direct medical as well as total costs [14, 15]. Hence, the choice of first-line therapy significantly affected the expenses borne by the family. The choice of first-line therapy, in turn, is affected by several factors such as affordability, the feasibility of daily injections, and monitoring, parental understanding and beliefs. Expensive first-line therapy (ACTH) had been used mostly by families with higher income. Despite receiving the cheapest first-line option, families 
Table 3 Disease-specific determinants of the total cost incurred by families of children with West syndrome

\begin{tabular}{|c|c|c|c|c|c|c|c|c|}
\hline \multirow[t]{2}{*}{ Factors } & \multirow[t]{2}{*}{ Variables } & \multirow[t]{2}{*}{$\mathrm{N}$} & \multirow[t]{2}{*}{ Median total cost in INR } & \multicolumn{2}{|l|}{ IQR } & \multicolumn{2}{|l|}{$95 \% \mathrm{CI}$} & \multirow[t]{2}{*}{$p$ value } \\
\hline & & & & Q1 & Q3 & Lower limit & Upper limit & \\
\hline Etiology & $\begin{array}{l}\text { Structural } \\
\text { Nonstructural }\end{array}$ & $\begin{array}{l}71 \\
14\end{array}$ & $\begin{array}{l}17,546 \\
28,223\end{array}$ & $\begin{array}{l}11,527 \\
15,004\end{array}$ & $\begin{array}{l}22,070 \\
37,010\end{array}$ & $\begin{array}{l}15,450 \\
20,714\end{array}$ & $\begin{array}{l}21,418 \\
33,212\end{array}$ & 0.13 \\
\hline Age at onset of epileptic spasms & $\begin{array}{l}\leq 5 \mathrm{mo} \\
>5 \mathrm{mo}\end{array}$ & $\begin{array}{l}24 \\
61\end{array}$ & $\begin{array}{l}12,886 \\
19,155\end{array}$ & $\begin{array}{l}6025 \\
14,431\end{array}$ & $\begin{array}{l}20,915 \\
26,572\end{array}$ & $\begin{array}{l}11,077 \\
18,298\end{array}$ & $\begin{array}{l}19,977 \\
25,039\end{array}$ & 0.14 \\
\hline Treatment lag & $\begin{array}{l}\leq 4 \mathrm{wk} \\
>4 \mathrm{wk}\end{array}$ & $\begin{array}{l}21 \\
64\end{array}$ & $\begin{array}{l}25,580 \\
17,258\end{array}$ & $\begin{array}{l}14,745 \\
10,665\end{array}$ & $\begin{array}{l}35,849 \\
22,093\end{array}$ & $\begin{array}{l}19,598 \\
15,125\end{array}$ & $\begin{array}{l}35,415 \\
19,836\end{array}$ & 0.13 \\
\hline Primary treatment & $\begin{array}{l}\text { ACTH } \\
\text { Oral steroids } \\
\text { Vigabatrin }\end{array}$ & $\begin{array}{l}58 \\
20 \\
7\end{array}$ & $\begin{array}{l}19,625 \\
6539 \\
19,557\end{array}$ & $\begin{array}{l}15,085 \\
4105 \\
14,459\end{array}$ & $\begin{array}{l}27,343 \\
12,918 \\
34,368\end{array}$ & $\begin{array}{l}19,141 \\
6230 \\
14,277\end{array}$ & $\begin{array}{l}25,545 \\
16,164 \\
33,282\end{array}$ & $<0.01^{*}$ \\
\hline Response to primary treatment & $\begin{array}{l}\text { Lack of complete response } \\
\text { Complete response }\end{array}$ & $\begin{array}{l}51 \\
34\end{array}$ & $\begin{array}{l}18,749 \\
18,265\end{array}$ & $\begin{array}{l}11,527 \\
12,141\end{array}$ & $\begin{array}{l}27,303 \\
22,186\end{array}$ & $\begin{array}{l}16,797 \\
14,981\end{array}$ & $\begin{array}{l}24,844 \\
21,753\end{array}$ & 0.89 \\
\hline Relapse $^{\mathrm{a}}$ & $\begin{array}{l}\text { No } \\
\text { Yes }\end{array}$ & $\begin{array}{l}27 \\
7\end{array}$ & $\begin{array}{l}18,695 \\
12,170\end{array}$ & $\begin{array}{l}12,450 \\
7547\end{array}$ & $\begin{array}{l}22,070 \\
30,769\end{array}$ & $\begin{array}{l}14,957 \\
7613\end{array}$ & $\begin{array}{l}21,476 \\
30,281\end{array}$ & 0.67 \\
\hline Comorbidities $^{\mathrm{b}}$ & $\begin{array}{l}\text { Absent } \\
\text { Present }\end{array}$ & $\begin{array}{l}46 \\
39\end{array}$ & $\begin{array}{l}18,965 \\
17,546\end{array}$ & $\begin{array}{l}12,382 \\
9935\end{array}$ & $\begin{array}{l}28,861 \\
23,020\end{array}$ & $\begin{array}{l}17,315 \\
14,291\end{array}$ & $\begin{array}{l}23,872 \\
23,606\end{array}$ & 0.58 \\
\hline
\end{tabular}

CI Confidence interval, INR Indian rupee, IQR Interquartile range, Q1 First quartile, Q3 Third quartile, USD US dollar

${ }^{*} p$ value $<0.05$ was considered statistically significant

${ }^{a}$ relapse was described only for those who initially showed complete response to primary therapy

${ }^{\mathrm{b}}$ Constipation, vision impairment, gastroesophageal reflux, hearing impairment, hemiparesis, infantile tremor syndrome, congenital heart disease, and hypothyroidism were considered

of children who received oral steroids went on to spend over $10 \%$ of their income. The Child Neurology Society and the South Asian West syndrome research group have suggested high-dose prednisolone as the preferred first-line therapy for WS during the coronavirus disease 2019 (COVID-19) pandemic to minimize healthcare visits $[16,17]$. This strategy can also prove beneficial from an economic point of view, especially for developing countries, including India. With the marked contraction of the Indian economy due to the pandemic containment measures, using oral steroids as the preferred first-line option may reduce the initial financial burden on families of affected children during this crisis. Regardless of the implementation of JSSK since 2014, many families in this study did not access free transport to public health institutions. Hence, there is a need to facilitate patient transport services under JSSK once the halted transport services commence.

Although the number of girls in this cohort was less, the fact that parents of girl-child spent equally on treatment as parents of boys was reassuring. The expenses borne by families were associated with parental education. This might be due to the relatively higher income of these families and due importance of health for educated parents. However, the expenses were not affected by the occupation, which is also an important determinant of income. Government assistance under the BPL scheme protected poor families from CHE and further impoverishment. It was interesting to note that none of the disease-related factors, except the choice of first-line therapy, significantly affected the total costs incurred.

Like the present study, the studies on cost-of-illness evaluation in various chronic childhood disorders like epilepsies, leukemia, and thalassemia have also concluded that the direct medical costs exceed the nonmedical costs $[14,15,18-20]$. Cost of drugs has been reported as the predominant part of the direct medical cost, which is again in concordance with previous studies $[14,15,18-20]$.

The present study assessing the financial spending on WS treatment is the first of its kind from the Indian subcontinent. Besides the epilepsy syndrome, the expenditure made on the treatment of comorbidities including cerebral palsy, constipation, visits made to ophthalmology and otorhinolaryngology specialists for assessment, and follow-up of disabilities was also taken into account because these comorbidities are an indispensable part of the care of such children. Unit cost was fixed for drugs and most services, thereby reducing the recall bias.

However, the present study is a single-center study. The subsidized rates from a public setup hospital may not apply to the hospitals in the private sector, which cater to India's significant healthcare needs [21]. The sample size was limited because of which, many potential factors affecting financial burden could not be assessed. The treatment expenditure was relatively lower in those with a long treatment lag, as expenditure assessment was performed until $1 \mathrm{y}$ from the onset of 
epileptic spasms. Besides, cost-effectiveness analysis and indirect costs estimation were not performed.

\section{Conclusion}

The present study provides a realistic magnitude of financial burden due to WS in the first year of illness. WS imposes substantial financial burden on the families and indirectly on the health system. The selection of ACTH therapy requiring initial inpatient care was a significant cost determinant. Further studies are warranted to quantify the indirect costs arising from the parents' loss of workdays, government expenditure, etc. Furthermore, cost-effectiveness analysis for different therapies, especially ACTH and oral steroids, may further help in identifying cost-effective strategies.

Supplementary Information The online version contains supplementary material available at https://doi.org/10.1007/s12098-021-03761-1.

Authors' Contribution DR: Study design, data acquisition, data interpretation, data analysis, prepared the initial draft of the manuscript and subsequent revision. SB, PM, SKR and SN: Data interpretation, data analysis, manuscript writing and final approval of the manuscript. LS, BB, and SP: Study design, interpretation of the data, data analysis and final approval of the manuscript. JKS: Concept, design, interpretation of the data, critical revision for intellectual content, and final approval of the manuscript. All authors approved the final version of the manuscript.

\section{Declarations}

Conflict of Interest None

\section{References}

1. Lux AL, Osborne JP. A proposal for case definitions and outcome measures in studies of infantile spasms and west syndrome: consensus statement of the west delphi group. Epilepsia. 2004;45: 1416-28.

2. Hunter MB, Yoong M, Sumpter RE, et al. Incidence of early-onset epilepsy: a prospective population-based study. Seizure. 2020;75: 49-54.

3. Datta V. Therapeutic hypothermia for birth asphyxia in neonates. Indian J Pediatr. 2017;84:219-26.

4. Sahu JK. Infantile spasms-evidence based medical management. Indian J Pediatr. 2014;81:1052-5.
5. Madaan P, Chand P, Linn K, et al. Management practices for west syndrome in South Asia: a survey study and meta-analysis. Epilepsia Open. 2020;5:461-74.

6. Sehgal R, Gulati S, Sapra S, Tripathi M, Kabra M, Pandey RM. Neurodevelopmental and epilepsy outcome in children aged one to five years with infantile spasms-a north Indian cohort. Epilepsy Res. 2014;108:526-34.

7. Vaddi VK, Sahu JK, Dhawan SR, Suthar R, Sankhyan N. Knowledge, attitude and practice (KAP) study of pediatricians on infantile spasms. Indian J Pediatr. 2018;85:836-40.

8. Amudhan S, Gururaj G, Satishchandra P. Epilepsy in India II: impact, burden, and need for a multisectoral public health response. Ann Indian Acad Neurol. 2015;18:369-81.

9. Gao L, Xia L, Pan SQ, Xiong T, Li SC. Burden of epilepsy: a prevalence-based cost of illness study of direct, indirect and intangible costs for epilepsy. Epilepsy Res. 2015;110:146-56.

10. Central Bureau of Health Intelligence. National Health Profile 2019. Available at: http://www.cbhidghs.nic.in/WriteReadData/ 1892s/8603321691572511495.pdf. Accessed on 19 Oct 2020.

11. Singhi P, Ray M. Profile of west syndrome in north Indian children. Brain and Development. 2005;27:135-40.

12. Angappan D, Sahu JK, Malhi P, Singhi P. Safety, tolerability, and effectiveness of oral zonisamide therapy in comparison with intramuscular adrenocorticotropic hormone therapy in infants with west syndrome. Eur J Paediatr Neurol. 2019;23:136-42.

13. Gulati S, Jain P, Kannan L, Sehgal R, Chakrabarty B. The clinical characteristics and treatment response in children with west syndrome in a developing country. J Child Neurol. 2015;30:1440-7.

14. Jensen MP, Brunklaus A, Dorris L, et al. The humanistic and economic burden of dravet syndrome on caregivers and families: implications for future research. Epilepsy Behav. 2017;70:104-9.

15. Thomas SV, Sarma PS, Alexander M, et al. Economic burden of epilepsy in India. Epilepsia. 2001;42:1052-60.

16. Grinspan ZM, Mytinger JR, Baumer FM, et al. Management of infantile spasms during the COVID-19 pandemic. J Child Neurol. 2020;35:828-34.

17. Sahu JK, Madaan P, Chand P, et al. Management of west syndrome during COVID-19 pandemic: a viewpoint from South Asian west syndrome research group. Epilepsy Res. 2020;167:106453.

18. Lagunju IA, Imam ZO, Adedokun BO. Cost of epilepsy in children attending a tertiary centre in Nigeria. Int Health. 2011;3:213-8.

19. Ghatak N, Trehan A, Bansal D. Financial burden of therapy in families with a child with acute lymphoblastic leukemia: report from North India. Support Care Cancer. 2016;24:103-8.

20. Esmaeilzadeh F, Azarkeivan A, Emamgholipour S, et al. Economic burden of thalassemia major in Iran, 2015. J Res Health Sci. 2016;16:111-5.

21. Sembiah S, Paul B, Dasgupta A, Bandyopadhyay L. Capacity building of private sector workforce for public health services in India: scope and challenges. Indian J Community Med. 2018;43: 144-7.

Publisher's Note Springer Nature remains neutral with regard to jurisdictional claims in published maps and institutional affiliations. 